Jurnal UJMC, Volume 6, Nomor 2, Hal. 21 - 27

pISSN : 2460-3333 eISSN : 2579-907X

\title{
Expected Value Premium Principle Pada Data Klaim Reasuransi
}

\author{
Radot MH Siahaan ${ }^{1}$, Dian Anggraini ${ }^{2}$, Andi.fitriawati ${ }^{3}$, \\ Dani Al Makhya ${ }^{4}$ \\ ${ }^{1}$ Prodi Sains Aktuaria, Institut Teknologi Sumatera, radot.siahaan@at.itera.ac.id \\ ${ }^{2}$ Prodi Sains Aktuaria, Institut Teknologi Sumatera, dian.anggraini@at.itera.ac.id \\ ${ }^{3}$ Prodi Sains Aktuaria, Institut Teknologi Sumatera, andi.fitriawati@at.itera.ac.id \\ ${ }^{4}$ Prodi Sains Aktuaria, Institut Teknologi Sumatera, dani.almakya@at.itera.ac.id
}

\begin{abstract}
The amount of stop loss cover reinsurance using krone as Danish currency. The stop loss cover reinsurance scheme with a retention value of $r=50$ million krone from fire insurance data in Denmark from 1980-1990 with truncate date at 10 million krone, resulting in a conditional expected value $\boldsymbol{P}=$ $\boldsymbol{E}\left[\boldsymbol{Y} \mid \boldsymbol{X}_{\boldsymbol{i}}>\boldsymbol{\partial}\right]$ that decreases in value when the higher the threshold value. This is indicated by the threshold value of $1=2.976$ resulting in pure premium of $1=$ 0.1217 , a threshold value of $2=10.0539$ resulting in pure premium $2=0.0867$ and a threshold value of $3=26.199$ resulting in pure premium $3=0.0849$. The use of expected value premium principle with the loading factor $(\theta=\mathbf{1 0} \%)$ is weighted to the value of the pure premium represented by $(\mathbf{1}+\boldsymbol{\theta}) \boldsymbol{E}\left[\boldsymbol{Y} \mid \boldsymbol{X}_{\boldsymbol{i}}>\boldsymbol{\partial}\right]$. This is indicated by the weight of premium $1=0.13387$, the weight of the premium 2 $=0.09537$ and the weight of premium $3=0.09339$
\end{abstract}

Keywords: Stop loss cover, threshold, General Pareto Distributions, Expected value premium principle

\begin{abstract}
Abstrak. Skema reasuransi stop loss cover dengan nilai retensi $r=50$ juta krone dan nilai cover maksimum reasuransi $\mathrm{R}=100$ juta krone dari data asuransi kebakaran di Denmark dari tahun 1980 - 1990 dengan krone sebagai satuan mata uang Denmark. Pemotongan (truncate) data di 10 juta krone menghasilkan nilai ekspetasi bersyarat $\boldsymbol{P}=\boldsymbol{E}\left[\boldsymbol{Y} \mid \boldsymbol{X}_{\boldsymbol{i}}>\boldsymbol{\partial}\right]$ yang semakin menurun nilainya ketika nilai threshold $\boldsymbol{u}$ semakin tinggi. Hal ini ditunjukan dengan nilai threshold $1=2.976$ menghasilkan premi murni $1=$ 0.1217 , nilai threshold $2=10.0539$ menghasilkan premi murni $2=0.0867$ dan nilai threshold $3=26.199$ menghasilkan premi murni $3=0.0849$. Penggunaan expected value premium principle dengan faktor loading $\boldsymbol{\theta}=\mathbf{1 0} \%$ dilakukan pembobotan pada nilai premi murni. Hal ini ditunjukan dengan bobot premi 1 $=0.13387$, bobot premi $2=0.09537$ dan bobot premi $3=0.09339$.
\end{abstract}

Kata Kunci: Stop loss cover, Threshold, General Pareto Distribution, Expected value premium principle

\section{Pendahuluan}

Skema reasuransi merupakan suatu metode yang digunakan perusahaan asuransi untuk melakukan transfer risiko terhadap klaim yang memiliki nilai yang besar kepada perusahaan reasuransi. Karakteristik klaim yang direasuransi memiliki frekuensi kejadian yang rendah (low frequency) namun menghasilkan kerugian yang tinggi (high severity) sehingga 
menghasilkan distribusi klaim yang mempunyai bentuk ekor yang tebal (heavy tail). Seperti yang terjadi pada kejadian bencana alam [1]. Untuk mengantisipasi terjadinya gagal bayar terhadap klaim-klaim dengan nilai besar tersebut, perusahaan asuransi melakukan reasuransi dengan skema stop loss cover. Melalui skema tersebut akan tercipta sebuah kontrak antara perusahaan asuransi dan reasuransi yang mewajibkan perusahaan asuransi untuk membayar klaim terjadi pada tingkat harga tertentu, sedangkan sisa dari kelebihan klaim tersebut akan dibayarkan oleh perusahaan reasuransi

Transfer risiko menggunakan mekanisme reasuransi stop loss cover mewajibkan perusahaan asuransi untuk membayar premi kepada perusahaan reasuransi. Besarnya premi yang dibayarkan dapat ditentukan dengan menghitung premi murni (pure premium) berdasarkan distribusi klaim yang telah dilakukan truncate melalui mekanisme stop loss cover. Apabila $X_{i}$ merepresentasikan suatu peubah acak dari besar klaim yang diasumsikan berdistribusi identik dan saling bebas (iid), $\mathrm{r}$ merupakan retensi (deductibles) dan $\mathrm{R}$ merupakan batas nilai klaim terbesar yang terjadi maka nilai-nilai klaim yang kan dibayarkan oleh perusahaan reasuransi adalah $Y_{i}=X_{i}-r$ untuk $r \leq X_{i} \leq R$ dan $Y_{i}=R-r$ untuk $X_{i}<\infty . Y_{i}$ dapat dipandang sebagai suatu peubah acak yang mempunyai distribusi tertentu.

Premi murni ditentukan melalui nilai ekspektasi $E\left[Y_{i}\right]$, namun tidak tertutup kemungkinan bahwa premi murni tidak cukup untuk menutup klaim yang dihadapi oleh perusahaan reasuransi dikarenakan distribusi hasil estimasi data klaim masa lampau seringkali tidak akurat untuk menggambarkan karakteristik klaim di masa yang akan datang. [2] memaparkan definisi premium principle yang merupakan prinsip untuk menentukan premi asuransi yang merupakan pencerminan dari transfer risiko. Terdapat tiga metode premium principle, yaitu: ad hoc method, characterization method dan economic method. Premi murni (net premium) masuk ke dalam kategori ad hoc method bersama dengan expected value premium principle, variance premium principle, standard variance premium principle, exponential premium principle, Esscher premium principle dan propotional hazard premium principle. Terdapat lima belas aksioma yang diharapkan dipenuhi oleh premium principles, namun hanya premi murni yang memenuhi lima belas aksioma tersebut.

Namun [3] menyatakan hanya cukup empat aksioma yang dibutuhkan agar premium principle memiliki sifat koheren. Ke-empat aksioma tersebut adalah Translational Invariance (T/TI), Subadditivity (S), Positive Homogenity $(\mathrm{PH})$ dan Monotonicity $(\mathrm{M})$. Premi murni merupakan satusatunya premium principle premium yang koheren. Namun perhitungan premi asuransi menggunakan premi murni hanya menghitung $E\left[Y_{i}\right]$, sedangkan premium principle lainnya melakukan pembobotan (weighted) terhadap $E\left[Y_{i}\right]$. Expected value premium principle merupakan premium principle yang tidak koheren dikarenakan tidak memenuhi satu aksioma, yaitu Transalational Invariance. Premi asuransi yang ditentukan menggunakan expected value premium principle lebih besar dari premi murni. Hal ini disebabkan adanya pembobotan (factor loading) yang menambah bobot nilai $E\left[Y_{i}\right]$. 
Berdasarkan pemaparan di atas, penulis tertarik untuk menentukan nilai premi menggunakan expected value premium principle pada data reasuransi dimana besarnya nilai ekspektasi $E\left[Y_{i}\right]$ sangat dipengaruhi oleh penentuan faktor loading. Faktor loading merupakan prosentase dari nilai ekspetasi $E\left[Y_{i}\right]$. Kemudahan penggunaan expected value premium principle dapat membantu perusahaan reasuransi dalam menghitung estimasi nilai premi yang akan dikenakan kepada perusahaan asuransi secara ringkas.

\section{Tinjauan Pustaka}

\subsection{Distribution Function of Truncated Data}

Data klaim perusahaan asuransi yang diobservasi oleh perusahaan reasuransi hanya data yang nilainya diatas nilai tertentu $(\partial)$. Setelah data dipotong (truncate), model distribusi kumulatif hasil pemotongan (truncate) pada data di suatu nilai tertentu[4]

$$
\mathbf{F}_{\mathbf{X}^{\mathbf{\partial}}}(\mathbf{X})=\mathbf{P}\{\mathbf{X} \leq \mathbf{X} \mid \mathbf{X}>\boldsymbol{\partial}\}=\left\{\begin{aligned}
\mathbf{0}, & \mathbf{x} \leq \mathbf{\partial} \\
\frac{\mathbf{F}_{\mathbf{X}}(\mathbf{X})-\mathbf{F}_{\mathbf{X}}(\boldsymbol{\partial})}{1-\mathbf{F}_{\mathbf{X}}(\boldsymbol{\partial})}, & \mathbf{x} \geq \mathbf{\partial}
\end{aligned}\right.
$$

Model distribusi kumulatif $X^{\partial}$ dapat ditaksir melalui data klaim masa lalu secara empiris dengan menggunakan empirical distribution function

$$
F_{n}(x)=\frac{1}{n} \sum_{i=1}^{n} 1_{\left(X_{i} \leq x\right)}
$$

dengan

$$
\mathbf{1}_{\left(X_{i} \leq x\right)}=\left\{\begin{array}{lll}
1 & , & X_{i} \leq x \\
0 & , & X_{i}>x
\end{array}\right.
$$

\subsection{Stop Loss Cover}

$X^{\partial}$ adalah suatu peubah acak yang merupakan realisasi dari data yang dipotong (truncated) di suatu nilai tertentu kemudian perusahaan reasuransi menetapkan nilai retensi (r) dan nilai maksimum klaim (R). Skema reasuransi dengan menggunakan stop loss cover didefinisikan sebagai berikut,

$$
Y=\left\{\begin{aligned}
0, & X^{\partial}<r \\
x-r, & r \leq X^{\partial} \leq R \\
R-r, & X^{\partial} \geq R
\end{aligned}\right.
$$

\subsection{Generalized Pareto Distribution (GPD)}

Data klaim setelah diberlakukan skema stop loss cover sangat sedikit, taksiran di ekor distribusi dari $X^{\partial}$ dapat ditentukan melalui metode peak over threshold (POT). Metode ini mensyaratkan pemilihan threshold $u$ yang nilainya cukup besar. Pemilihan nilai $u$ dilakukan dengan mencari nilai presentil dari data klaim. Pemilihan nilai threshold $u$ akan membuat 
suatu peubah acak bersyarat $P\left(X^{\partial}-u \mid X^{\partial} \geq u\right)$ yang memiliki distribusi pendekatan (limiting distribution) Generalized Pareto[5]

$$
\boldsymbol{P}\left\{\boldsymbol{X}^{\boldsymbol{\partial}}-\boldsymbol{u} \mid \boldsymbol{X}^{\boldsymbol{\partial}}>\boldsymbol{u}\right\} \rightarrow^{\boldsymbol{d}} \boldsymbol{G}_{\xi, \boldsymbol{\sigma}}(\boldsymbol{X})
$$

dengan

$$
G_{\xi, \sigma}(x)=1-\left(1+\xi \frac{x-u}{\sigma}\right)^{-\frac{1}{\xi}}
$$

Dengan $\xi \neq 0$ dan $\sigma>0$

\subsection{Fitting GPD Pada Ekor Distribusi $X^{\partial}$}

Jika distribusi bersyarat $P\left(X^{\partial}-u \mid X^{\partial} \geq u\right)$ dapat difitting dengan distribusi Generalized Pareto dengan nilai threshold u yang besar maka ekor dari distribusi $X^{\partial}$ dapat difitting dengan menggunakan distribusi Generalized Pareto [6]. Berikut adalah model ekor distribusi $X^{\partial}$ dengan $x \geq u$

$$
F_{X^{\partial}}(x)=P(X \leq x)=(1-P\{X \leq u\}) F_{u}(x-u)+P\left(X^{\partial} \leq u\right)
$$

\subsection{Uji Kecocokan Model}

Uji kecocokan model perlu dilakukan untuk melihat apakah model Generalized Pareto yang ditaksir dengan nilai threshold $u$ tertentu cocok dengan data. Uji kecocokan model menggunakan uji Cramer-Von-Mises dan uji Anderson Darling [7] dengan hipotesa

$\mathrm{H}_{0}=$ Data mengikuti distribusi Generalized Pareto distribution

$\mathrm{H}_{1}=$ Data tidak mengikuti distribusi Generalized Pareto distribution

Berikut adalah statistik uji Cramer-Von-mises

$$
W^{2}=\sum_{i=1}^{n}\left\{F\left(x_{i}\right)-\frac{2 i-1}{2 n}\right\}^{2}+\frac{1}{12 n}
$$

Berikut adalah statistik uji Anderson-Darling

$$
A^{2}=-n-\frac{1}{n} \sum_{i=1}^{n}(2 i-1)\left[\log \left(1-F\left(x_{n+1-i}\right)\right]\right.
$$

\subsection{Expected Value Bersyarat Distribusi Generalized Pareto}

Apabila nilai retensi (r) dan nilai maksimum (R) ditentukan, premi murni (net premium) dapat dihitung dengan mencari nilai ekspektasi $E\left[Y \mid X_{i}>\partial\right]$, yaitu

$$
P=\int_{r}^{R}(x-r) f_{X^{\delta}}(x) d x+(R-r)\left(1-F_{X^{\delta}}(R)\right)
$$

Nilai $\boldsymbol{f}_{X^{\partial}}(\boldsymbol{x})=\frac{\boldsymbol{d} \boldsymbol{F}_{X^{\partial}}(\boldsymbol{x})}{\boldsymbol{d} \boldsymbol{x}}$ menyatakan fungsi kepadatan peluang klaim yang dipotong di $\boldsymbol{\partial}$. Jika nilai threshold $\boldsymbol{u}<\boldsymbol{r}$ dipilih dan kemudian dilakukan fitting 
dengan model distribusi Generalized Pareto maka estimasi dari fungsi distribusi kumulatif Genaralized Pareto dengan $\boldsymbol{x}>\boldsymbol{u}$

$$
\widehat{\boldsymbol{F}}_{\boldsymbol{X}^{\partial}}=\left(\mathbf{1}-\boldsymbol{F}_{\boldsymbol{n}}(\boldsymbol{u})\right) \boldsymbol{G}_{\widehat{\xi}, \boldsymbol{u}, \widehat{\sigma}}(\boldsymbol{x})+\boldsymbol{F}_{n}(\boldsymbol{u})
$$

\subsection{Expected Value Premium Principle}

Nilai premi mengikuti kaidah expected value premium dapat dihitung dengan menggunakan [8]

$$
\mathcal{H}(\boldsymbol{x})=(\mathbf{1}+\boldsymbol{\theta}) \boldsymbol{P}
$$

dimana $\mathcal{H}(X)$ merupakan fungsi premium principle yang memetakan anggota domain yang ada di model distribusi $P[Y \mid X>\partial]$. $\theta$ merupakan factor loading yang memboboti nilai $P$ sehingga akan dihasilkan $\mathcal{H}(X) \geq \mathrm{P}$

\section{Metode Penelitian}

Data yang digunakan pada penelitian sebelumnya menggunakan data sekunder yang merupakan data besar klaim (severity) dari perusahaan reasuransi Denmark sebanyak 2167 data yang dicatat dari tahun 1980 - 1990. Data klaim masih bersifat ground-up loss yang berarti data klaim tersebut belum dikurangi oleh nilai $\partial$ yang merupakan nilai klaim yang tidak dipertimbangkan oleh perusahaan reasuransi. Metode penelitian menggunakan kaidah expected value premium principle untuk menghitung premi risiko dari skema asuransi stop loss cover dengan nilai retensi (r) sebesar 50 juta krone dan nilai maksimum klaim (R) yang disepakati sebesar 100 juta krone.

\section{Pembahasan}

\subsection{Estimasi Parameter dan Uji Kecocokan Model Generalized Pareto}

Data klaim dipotong (truncated) dengan nilai displacement $\partial$ sebesar 10 juta krone. Nilai selang [r,R] yang akan digunakan adalah [50,100], dimana $\mathrm{r}$ sebesar 50 juta krone merupakan retensi yang ditahan oleh perusahaan asuransi, sedangkan $\mathrm{R}$ sebesar 100 juta krone nilai maksimum klaim.

Penentuan nilai threshold $u$ dilakukan dengan menghitung persentil ke-75, ke-95 dan ke-99 dari data klaim sebelum dipotong (truncated). Setelah dilakukan simulasi untuk menentukan taksiran parameter distribusi Generalized Pareto dan diuji kecocokan modelnya dengan menggunakan uji Cramer-Von-mises dan uji Anderson-Darling maka didapat hasilnya dapat dilihat pada tabel berikut

Tabel 1. Hasil estimasi parameter GPD dan Uji kecocokan model GPD

\begin{tabular}{lllllll}
\hline No & Persentil & Threshold u & $\xi$ & $\sigma$ & $\mathrm{W}^{2}$ (p-value) & $\mathrm{A}^{2}$ (p-value) \\
\hline 1 & $75 \%$ & 2.9726 & 0.6687 & 2.1667 & $0.0835(>0.25)$ & $0.5554(>0.25)$ \\
2 & $95 \%$ & 10.0539 & 0.495 & 5.0324 & $0.0336(>0.5)$ & $0.2762(>0.5)$ \\
3 & $99 \%$ & 26.199 & 0.8908 & 10.1613 & $0.0289(>0.5)$ & $0.2715(>0.5)$ \\
\hline
\end{tabular}




\subsection{Perbandingan Premi Murni dengan Expected Value Premium Principle}

Dengan menggunakan komputasi, hasil uji statistik menunjukan bahwa distribusi Generalized Pareto dengan masing-masing nilai threshold merupakan model distribusi yang cocok untuk memodelkan data klaim. Distribusi Generalized Pareto cocok untuk menjadi model dari distribusi klaim bersyarat $P\left(X^{\partial}-u \mid X^{\partial} \geq u\right)$ maka model distribusi Generalized Pareto dapat digunakan untuk memodelkan ekor distribusi klaim yang nilainya melebihi dari threshold $u$ dimana taksiran model distribusinya ditentukan oleh persamaan ke-11. Hal ini akan sangat berguna untuk menghitung nilai ekspektasi bersyarat $P=E\left[Y \mid X_{i}>\partial\right]$ yang merupakan nilai premi murni (net premium).

Berikut adalah perbandingan antara nilai premi murni dengan premi yang telah diboboti dengan faktor loading $\theta$ sebesar $10 \%$ dari nilai premi murni dan selang $[\mathrm{r}, \mathrm{R}]$ ditentukan sebesar $[50,100]$.

Tabel 2. Nilai premi murni dan premi dengan faktor loading

\begin{tabular}{llllll}
\hline No & Threshold u & $\xi$ & $\sigma$ & $E\left[Y \mid X_{i}>\delta\right]$ & $H(X ; \theta)$ \\
\hline 1 & 2.9726 & 0.6687 & 2.1667 & 0.1217 & 0.13387 \\
2 & 10.0539 & 0.495 & 5.0324 & 0.0867 & 0.09537 \\
3 & 26.199 & 0.8908 & 10.1613 & 0.0849 & 0.09339 \\
\hline
\end{tabular}

Dengan bantuan komputasi, nilai premi murni dihitung dengan menggunakan persamaan (11) yang merupakan nilai ekspektasi bersyarat $P=E\left[Y \mid X_{i}>\partial\right]$. Tabel 2 menunjukan bahwa semakin besarnya nilai threshold $u$ akan mengakibatkan nilai premi murni semakin mengecil.

Terdapat dua pilihan solusi untuk meningkatkan premi murni. Pilihan pertama adalah dengan menurunkan nilai threshold $u$, namun pilihan tersebut tidak direkomendasikan dikarenakan semakin tinggi nilai threshold $u$ maka ekor distribusi $P[Y \mid X>\partial]$ dapat dimodelkan dengan menggunakan model distribusi Generalized Pareto.

Pilihan kedua adalah dengan melakukan pembobotan nilai premi murni dengan faktor loading sebesar $\theta=10 \%$ dengan menggunakan persamaan (12). dimana selang $[r, R]$ sebesar $[50,100]$. Bila dibandingkan dengan nilai premi murni terjadi peningkatan besar premi ketika dihitung dengan menggunakan kaidah expected value premium principle. Pemilihan nilai $\theta=10 \%$ merupakan asumsi adanya peningkatan nilai $P=$ $E\left[Y \mid X_{i}>\partial\right]$ sebesar $10 \%$ di periode mendatang. Karena masih bersifat asumsi makanya nilai $\theta$ bersifat subyektif dan bergantung kepada justifikasi perusahaan.

\section{Kesimpulan}

Penentuan nilai premi murni untuk skema reasuransi dengan menggunakan stop loss cover mensyaratkan penetapan nilai threshold $u$ yang tinggi agar ekor distribusi $P[Y \mid X>\partial]$ dapat dimodelkan dengan menggunakan model distribusi Generalized Pareto (GPD). Sebagai langkah 
antisipasi dalam menghadapi peningkatan klaim, penggunaan expected value premium principle dilakukan untuk menambah bobot dari premi murni dengan menggunakan faktor loading $\theta$. Walaupun expected value premium principle bukan merupakan suatu premium principle yang koheren, namun kemudahan implementasi dapat digunakan untuk membuat estimasi premi.

Saran untuk penelitian selanjutnya adalah menemukan metode yang tepat untuk pemilihan nilai threshold $u$ yang tepat dan melakukan perbandingan antara kaidah premium principle lainnya.

\section{Daftar Pustaka}

[1] Anggraini, D., Wijaya, Y. (2016). Obligasi Bencana Alam dengan Suku Bunga Stokastik dan Pendekatan Campuran. Al-Jabar: Jurnal Pendidikan Matematika, Vol.7, No. 1,2016, 49-62

[2] Young, V. R. (2004). Premium Principles. Encyclopedia of Actuarial Science.

[3] Artzner, P., Delbaen, F., Eber, J., Heath, D. (1999), Coherent Measure of Risk, Mathematical Finance, Vol 9, No. 3, 203-228

[4] Klugman S., Hogg R. (1984). Loss Distributions, Wiley \& Sons

[5] McNeil, J. (1996), Estimating the Tails of Loss Severity Distribution using Extreme Value Theory, Zurich

[6] Reiss, R and Thomas, M (1996) Statistical analysis of extremes values, The annals of Statistics 3, 119-131

[7] Klugman, Panjer, Wilmott, Loss Models : from Data to Decisions $4^{\text {th }}$

[8] Lestia, A. (2011), "Ukuran Risiko untuk Beberapa Model Peluang”, Bandung : Tesis Magister Aktuaria ITB 